\section{The lonely endemic Palni Hills RUDRAKSHA TREE ELAEOCARPUS BLASCOI WEIBEL (MAGNOLIOPSIDA: MALVALES: ELAEOCARPACEAE), TAMIL NADU, INDIA}

\author{
Dhanaraj Felix Irudhayaraj ${ }^{1} \&$ Raju Ramasubbu ${ }^{2}$ \\ 1,2 Department of Biology, The Gandhigram Rural Institute, \\ Gandhigram, Tamil Nadu 624302, India \\ ${ }^{1}$ felixirudhyaraj6@gmail.com (corresponding author), \\ 2racprabha@yahoo.com
}

In India, the species of Elaeocarpus are confined mostly to northeastern and southern India and a few species in Andaman and Nicobar Islands. Six species, viz., E. blascoi, E. gaussenii, E. glandulosus, E. munroii, E. recurvatus and $E$. venustus, are endemic to southern peninsular India. A few species show restricted distribution in the subcontinent, viz.: E. amoenus located in southern India and Sri Lanka; $E$. acuminatus and $E$. prunifolius found in India and Bangladesh; E. braceanus, E. bracteatus, E. grandifolius and $E$. helferi in India and Myanmar and E. sikkimensis from northeastern India and Bhutan. The species generally prefer a warm humid climate and usually occur between 500-2000 m. Though widely distributed, they are never found in abundance in any particular locality. The fruits of Elaeocarpus are edible and the fruits of $E$. sphaericus are used as beads for rosaries, bracelets and necklaces and also for their purported magico-religious properties (Weibel 1968; Sharma \& Sanjappa 1993).
Most of the members of the family Elaeocarpaceae have indolizidine alkaloid compounds, which have attracted a great deal of interest on account of their ability to inhibit the enzymatic activity of glucosidases. Hence, there is some potential to explore it further in the treatment

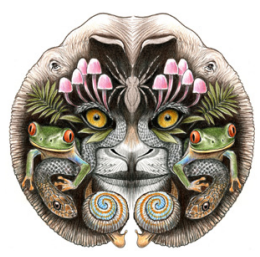

ISSN 0974-7907 (Online) ISSN 0974-7893 (Print)

\section{OPEN ACCESS} of AIDS, diabetes and cancer (Wiart 2006). The fruits of Elaeocarpus species are endowed with a hard and highly ornamental stony endocarp. In nature, the germination of nuts in most of the Elaeocarpus species is very low and erratic, since nuts are unable to imbibe water (Bhuyan et al. 2002). Poor or no germination coupled with prolonged dormancy owing to the hardness of the endocarp cause a significant reduction in the regeneration of several Elaeocarpus species (Khan et al. 2003).

Elaeocarpus blascoi, a large shola tree that was first discovered in Bear Shola of Palni Hills, Tamil Nadu in 1970 was later found to be extinct during the exploration of the flora of Palni Hills (Mathew 1999). Fortunately, it was rediscovered in another region of the Kodaikanal forests in $\mathbf{2 0 0 0}$ with only one living individual. It is a strict endemic species to Palni Hills of Western Ghats found on the fringes of the moist evergreen forest above 2,150m and included under Endangered category (World Conservation Monitoring Centre 1998). Elaeocarpus blascoi is a canopy tree growing up to $20 \mathrm{~m}$ tall in moist evergreen forests with short young branchlets appearing grey with silky hairs and fallen leaf scars (Images 1a-h).
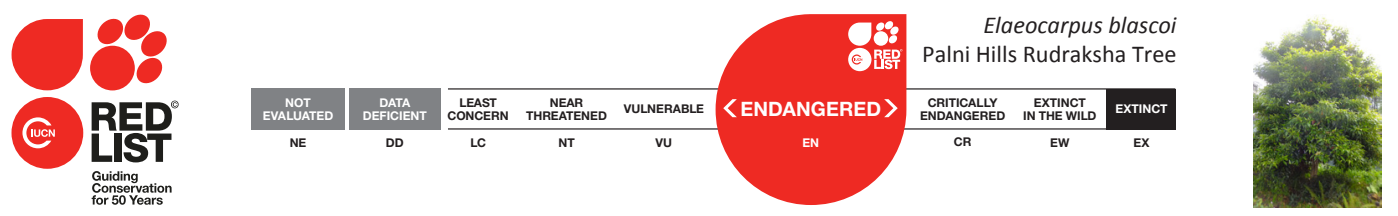

DOI: http://dx.doi.org/10.11609/JoTT.04067.6473-6

Editor: N.P. Balakrishnan, Ret. Joint Director, BSI, Coimbatore, India.

Date of publication: 26 October 2014 (online \& print)

Manuscript details: Ms \# 04067 | Received 21 June 2014 | Final received 02 October 2014 | Finally accepted 05 September 2014

Citation: Irudhayaraj, D.F. \& R. Ramasubbu (2014). The lonely endemic Palni Hills Rudraksha Tree Elaeocarpus blascoi Weibel (Magnoliopsida: Malvales: Elaeocarpaceae), Tamil Nadu, India. Journal of Threatened Taxa 6(11): 6473-6476; http://dx.doi.org/10.11609/JoTT.04067.6473-6

Copyright: ( ) Irudhayaraj \& Ramasubbu 2014. Creative Commons Attribution 4.0 International License. JoTT allows unrestricted use of this article in any medium, reproduction and distribution by providing adequate credit to the authors and the source of publication.

Funding: DST - Inspire Fellowship Programme

Competing Interest: The authors declare no competing interests.

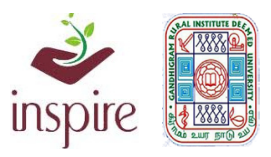

Acknowledgements: We thank the Department of Science and Technology, New Delhi for providing fund under INSPIRE Fellowship Programme (IF130195) to carryout the research. Authors thank Mr. M. Michael, VOYCE, Kodaikkanal for the assistance during filed trip. 
Tender parts are sericeous. Leaves simple, ovate-elliptic or elliptic, alternate in arrangement, clustered at twig apices, coriaceous, obscurely serrate, obtuse at base, acute at apex, glabrous above, sparsely appressed hairy or glabrescent beneath, with prominent veins beneath. Stipules caducous and petioles $1.5-2.5 \mathrm{~cm}$ long with sparsely appressed hairs. The midrib is slightly raised above; secondary nerves with seven pairs, branched with domatia in the axils beneath; tertiary nerves reticulapercurrent. Inflorescence axillary or terminal racemes with 6-7 white flowers, flower-buds ovoid, acute, more or less densely short sericeous, glabrate. Sepals 10-11 mm long, lanceolate, acute, densely short sericeous outside, velvety along margin, petals $12 \mathrm{~mm}$ long, five, broader towards apex, laciniate into 11-14 segments, densely sericeous outside. Stamens, densely appressed hirtellous; filaments 2-3.3 mm long; anther 2.5-4 mm long, anthers bearded, not ciliate, anther tip produced into a subulate, $1 \mathrm{~mm}$ long awn. Disc annular, 10-lobed. Ovary densely sericeous, 2-3 loculed; ovules six in each locule; styles sericeous at base, 6-6.5 mm long. Fruits are drupes, $1.5 \mathrm{~cm}$ long, ellipsoid, round at base and apex, laterally scarcely compressed, one-seeded (Table 1). It flowers in the month of January and sets fruits in September (Image 1b). But we found some oscillation in the flowering and fruiting period from January to May.

Observations: The present study on exploration and observations on individuals of $E$. blascoi was conducted throughout Palni Hills from July 2012 to May 2014. The results from the study confirmed that there was only one mature individual at present in the wild at Vattakanal Shola $\left(10^{\circ} 12^{\prime} 29.602^{\circ} \mathrm{N} \& 77^{\circ} 28^{\prime} 50.328^{\circ} \mathrm{E}\right)$ at an altitude of $2,011 \mathrm{~m}$. Two individuals are under the conservation of an NGO. One individual planted in the NGO garden (Vattakanal Conservation Trust, Pambarpuram, Kodaikanal), and the other one planted by the road side (on the way to Dolphin Nose, Vattakanal, Kodaikanal). Elaeocarpus blascoi also has a very slow growth rate. It takes more than 15 years to start flowering.

Leaf: During the emergence of the young shoot tips, tender shoots were infected by unidentified insects (aphids/ticks) which affect the growth of new branches (Images 1d,e). As it is a shola tree there is no leaf shedding. Mature leaves fall when they attain a deep red color as in other Elaeocarpus species.

Flowers and fruits: During the peak flowering period, preliminary studies on 50 inflorescence of E. blascoi were marked for successful natural fruit setting. The total number of flowers per inflorescence was counted and the number of flowers that formed fruit were analyzed. There was no premature fruit fall during fruit development. The fruit development takes place from the month of February along with leaf flushing. The fruit matures in the month of June and gets detached continuously from the stalk.

Seeds: Seeds from various years were found under the tree canopy (Image 1c). Seeds are highly ornamented as in other species of Elaeocarpus with a hard endocarp. Some of the seeds fully lost their viability within one year after the detachment from mother plant. The preliminary seed biological studies showed only $48 \%$ of seeds were viable. Seeds consist of three carpels and only two of the three embryos successfully developed even though they were affected by some unknown fungal infection inside. Seedlings were not found in the natural habitat near the tree.

Seedlings were not found in the natural habitat near the tree. The tree in the natural habitat faces severe threats due to various factors such as loss of natural habitat due to the extension of social forestry and monoculture of exotic trees, and extension of agricultural land in the natural forest area. Alien trees like Acacia mearnsii, $A$. decurrans, $A$. dealbata, $A$. melanoxylon, Pinus radiata, $P$. ponderosa, $P$. sabiniana, $P$. roezlii, Eucalyptus grandis and $E$. saligna create severe damage to the tree and its seedlings.

The preliminary studies on seed propagation and conservation of species in the natural habitat did not yield good results. But the periodical effort on the propagation of this little known species have produced a few saplings and only one individual survives at present in the wild. An air layering trial was also conducted by Pavendan et al. (2012) on E. blascoi, which showed that the pre-monsoon season (mid-March to mid-June) seems to be the best period for air layering in E. blascoi. Air layering was

Table 1. Floral characters

\begin{tabular}{|l|l|}
\hline Floral Characters & Observation \\
\hline Inflorescence & Axillary or terminal racemes \\
\hline $\begin{array}{l}\text { Mean no. of flowers per } \\
\text { inflorescence }\end{array}$ & $5.2 \pm 0.7$ \\
\hline Flower & Hermaphrodite, Actinomorphic \\
\hline Flowering period & December to January \\
\hline Flower color & Silky white, corolla with segmented tip \\
\hline Odour & Absent \\
\hline Flower opening & Between 0700-1100hrs \\
\hline Anther dehiscence & $2-4$ hours after anthesis \\
\hline Mean no. of anthers per flower & $26 \pm 6$ \\
\hline Pollen grain shape & Spherical \\
\hline Pollen type & Tri-colporate \\
\hline Stigma type & Wet type \\
\hline
\end{tabular}




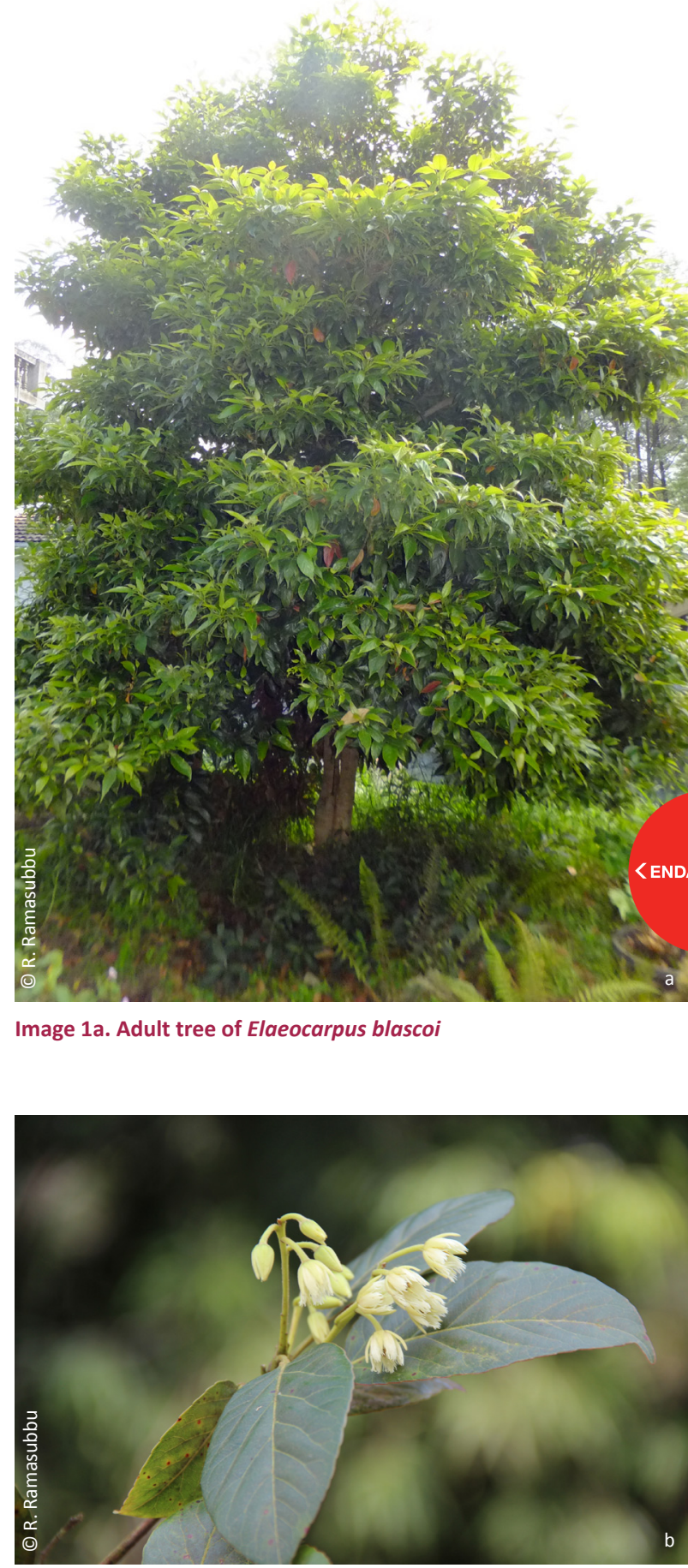

Image 1b. Flowering twig

successfully established in E. blascoi, although there has been no effective action taken to raise the tree saplings. The saplings are conserved in green house, Department of Biology, Gandhigram Rural Institute.

Conclusion: In this situation, E. blascoi needs the attention of conservation biologists for the application of modern conservation tools. Various propagation

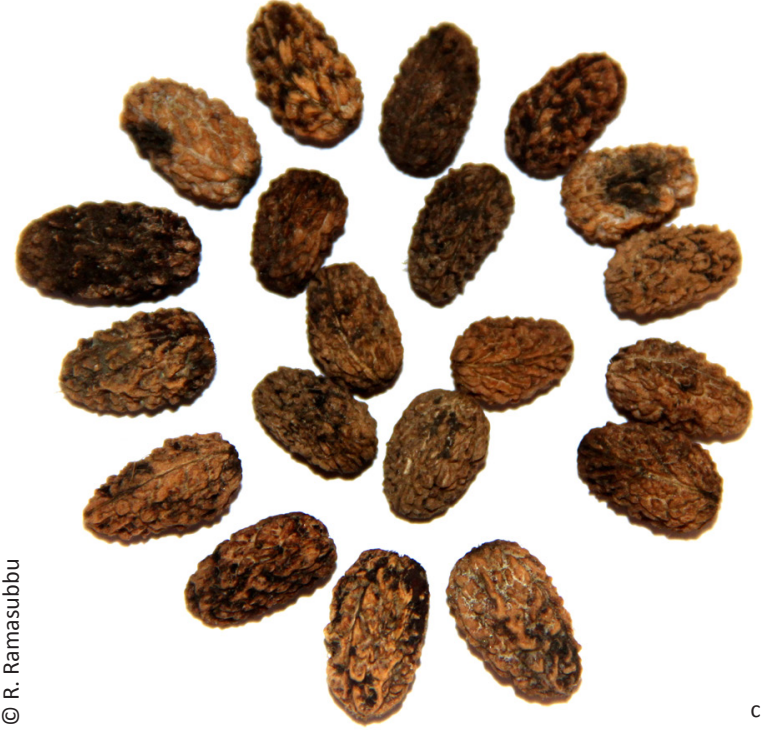

Image 1c. Mature seeds

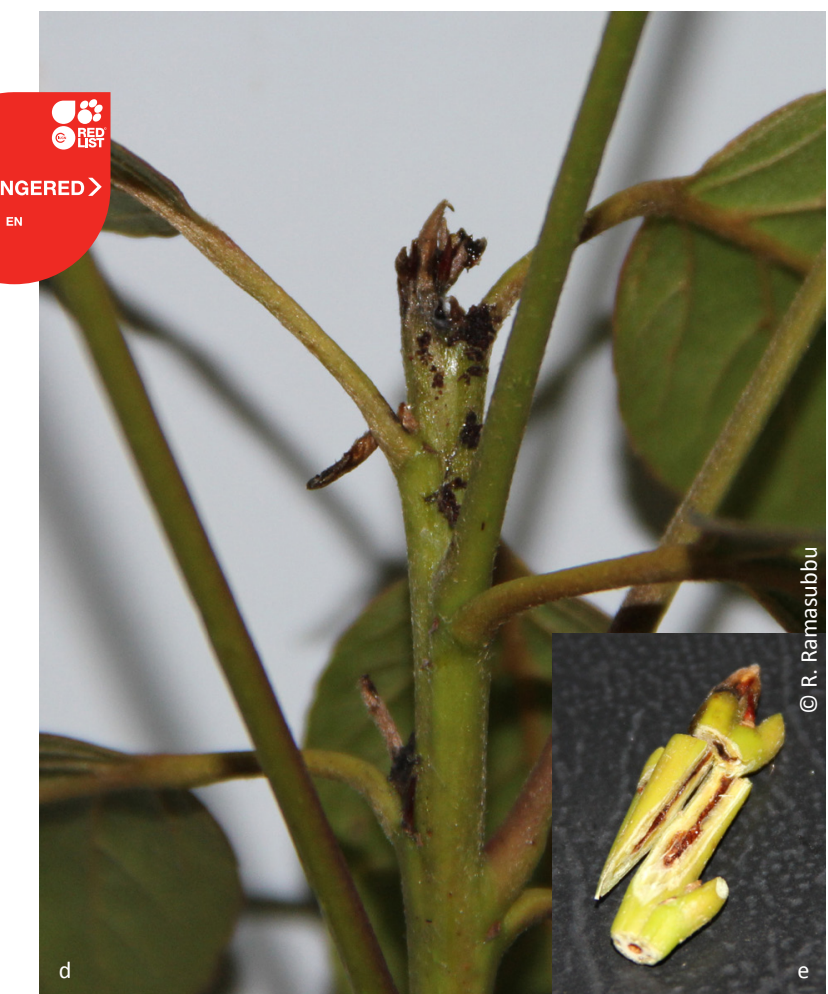

Images 1d - Infested tender shoot; 1e - Infested tender shoot inner view

techniques and tissue culture techniques are required to raise the saplings in mass. Reproductive biological studies are also very important to identify their reproductive constraints, mode of pollination, reproductive capacity, which will be helpful to identify the problems that they face in their natural habitat. Seed biological studies are also needed for the faster regeneration. By taking 


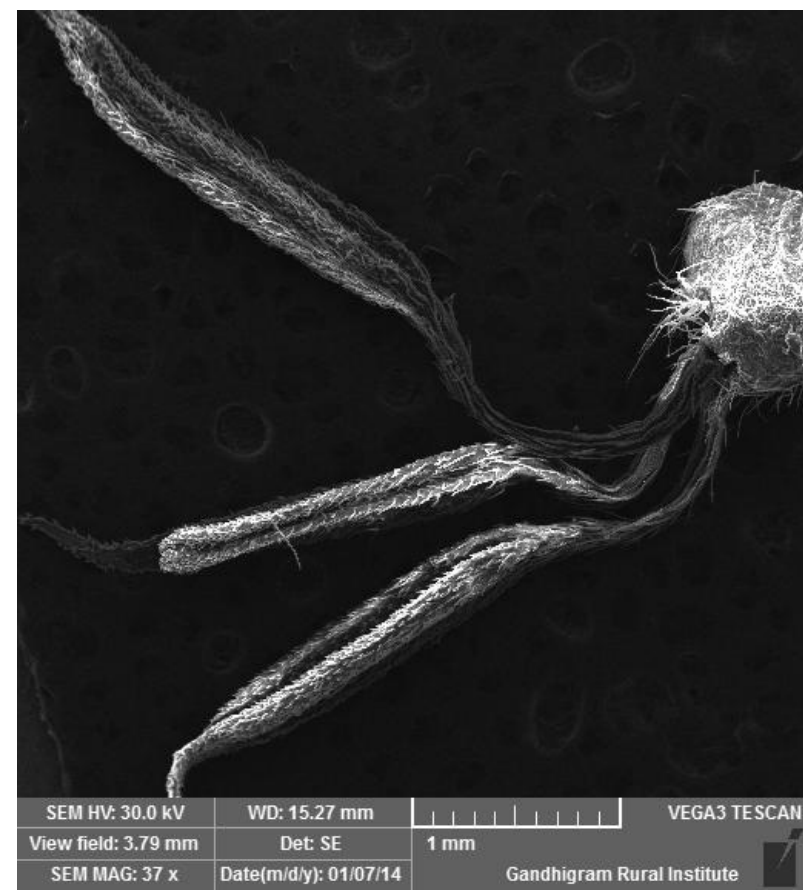

Image 1f. SEM of anthers

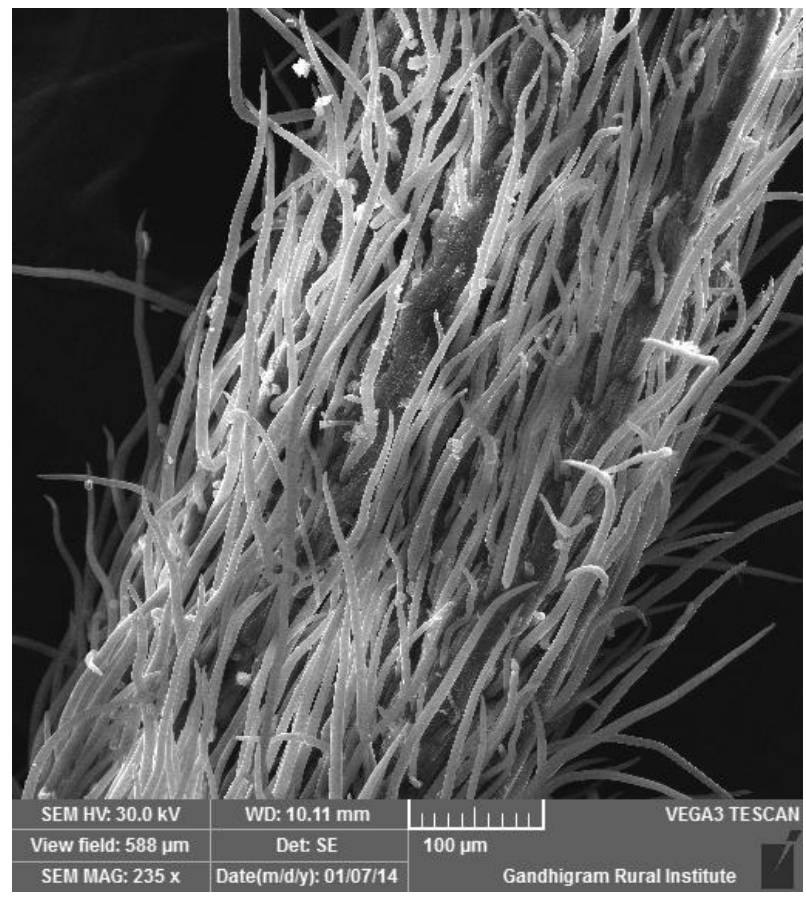

Image 1h. SEM image of style: closer view

effective strategies to conserve this valuable endemic tree E. blascoi, it can be protected from extinction and for the benefit of our future generations. The conservation status based on the present knowledge of the species indicates that it is Critically Endangered and not just Endangered as

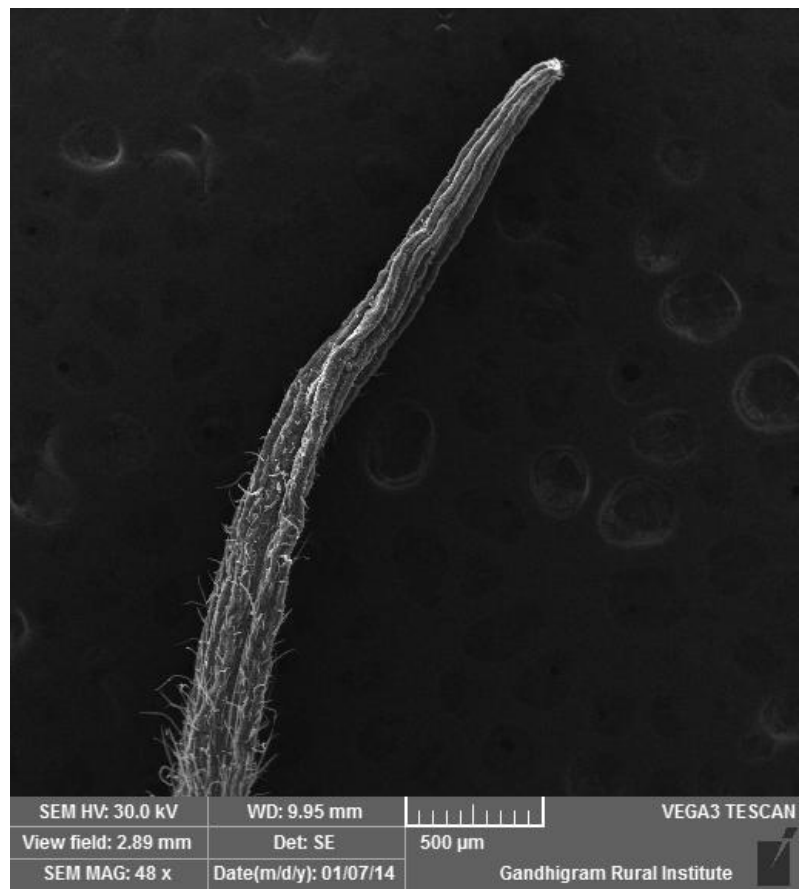

Image 1g. SEM of style

the assessment shows. The status needs to be reassessed and updated on the IUCN Red List immediately, with only one known mature individual surviving in the wild. If urgent conservation measures are not undertaken the species could become extinct due to threats and unknown limiting factors.

\section{References}

Bhuyan, P., M.L. Khan \& R.S. Tripathi (2002). Regeneration status and population structure of Rudraksh (Elaeocarpus ganitrus Roxb.) in relation to cultural disturbances in tropical wet evergreen forest of Arunachal Pradesh. Current Science 83: 1391-1394.

Khan, M.L., P. Bhuyan \& R.S. Tripathi (2003). Regeneration of Rudraksh (Elaeocarpus ganitrus Roxb.) - a threatened tree species: germination strategies. International Journal of Ecology and Environmental Science 29: 255-260.

Mathew, K.M. (1999). The Flora of Palni Hills, South India. Part 1 Polypetalae. The Rapinat Herbarium, Tiruchirapalli, 145-146pp.

Pavendan, P., V.A. Gideon \& S.C. Rajasekaran (2012). Cost effective ex situ conservation (Airlayering) of Elaeocarpus blascoi an endangered medicinal tree in Western Ghats of Palni Hills, Tamil Nadu, South India. The Indian Forester 138(11): 1056-1058.

Sharma, B.D. \& M. Sanjappa (1993). Flora of India: Portulacaceae Ixonanthaceae, Botanical Survey of India, Calcutta, iii+529pp.

Weibel, R. (1968). Morphologie de l' embryonet de la graine des Elaeocarpus. Candollea 23: 101-108.

Wiart, C. (2006). Medicinal plants of Asia and The Pacific. CRC/Taylor \& Francis, Boca Raton, 87pp.

World Conservation Monitoring Centre (1998). Elaeocarpus blascoi. The IUCN Red List of Threatened Species. Version 2014.2. <www. iucnredlist.org>. Downloaded on 10 October 2014

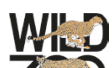

